\title{
LOS REGÍMENES ALIMENTARIOS DE LAS COMUNIDADES INDÍGENAS AMAZÓNICAS Y SUS IMPACTOS MEDIOAMBIENTALES
}

\author{
THE FOOD REGIMES OF THE INDIGENOUS AMAZON \\ COMMUNITIES AND THEIR ENVIRONMENTAL IMPACTS
}

\author{
Rafael Cartay \\ Universidad Técnica de Manabí (UTM), Ecuador
}

Aceptado: 2 de setiembre de 2018

\section{RESUMEN}

El comportamiento alimentario de un grupo opera como una estrategia cultural para asegurar la sobrevivencia, reconocerse dentro de una cultura que cambia constantemente, pero que, insertándose en la tradición mantiene una identidad cultural que cohesiona el grupo y lo diferencia de otros. El comportamiento alimentario o régimen alimentario es la expresión de estructuras de poder, prestigio de grupo y de sistemas de subordinación en el largo plazo, en el que se consumen sustancias que presentan una triple dimensión como nutriente, medicamento y símbolo. En este artículo se discute sobre los impactos causados al medio ambiente por los regímenes alimentarios, y las posturas de los críticos del Ecologically Noble Savage, sosteniendo que las comunidades indígenas nativas amazónicas de escaso contacto con la sociedad urbana y el mercado, producen moderados daños ecológicos mientras contribuyen con la ampliación de la biodiversidad de su entorno en algunos aspectos.

Palabras clave: régimen alimentario amazónico, prácticas culturales alimentarias, Ecologically Noble Savage, biodiversidad.

\begin{abstract}
The alimentary behavior of a group operates as a cultural strategy to ensure survival, recognizing itself within a culture that changes constantly, but that by inserting itself in the "tradition" maintains a cultural identity, which unites the group and differentiates it from others. The alimentary behavior or diet is the expression of structures of power, prestige of group and systems of subordination in the long term, in which substances that have a triple dimension as a nutrient, medicine and symbol are consumed. This article discusses the impacts caused to the environment by diets, and the positions of the critics of the Ecologically Noble Savage, arguing
\end{abstract}

Este es un artículo Open Access bajo la licencia Creative Commons AtribuciónNoComercial-Compartirlgual 4.0

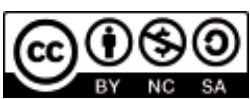


that indigenous Amazonian communities with little contact with urban society and the market produce moderate ecological damage, while they contribute to the expansion of the biodiversity of their environment in some aspects.

Keywords: Amazonian diet, food cultural practices, Ecologically Noble Savage, biodiversity.

\section{Introducción}

Se ingieren alimentos para sobrevivir. Nutrientes necesarios para desarrollar la potencialidad que significa ser dentro de un cuerpo biológico. Una necesidad que solventamos, dada nuestra condición de omnívoro, consumiendo unos grupos diferenciados de nutrientes para mantenernos saludables y cumplir adecuadamente las funciones propias de la fisiología humana. No solo se necesitan distintas clases de nutrientes alimentarios, sino que, al mismo tiempo, se requiere consumir una cantidad adecuada y suficiente de calorías. Cantidad que depende de las características de cada individuo (sexo, edad, estatura, actividad realizada, perfil psicológico, etc.) para proveerle, cada día, de la energía necesaria que requiere el mantenimiento de su vida a un nivel satisfactorio y adecuado.

Se come, además, como una importante manifestación social para reconocerse dentro de una cultura que está sujeta a una constante evolución. En medio de los cambios que amenazan con desintegrar al grupo, sus miembros buscan cohesionarse como una entidad cultural, anclándose en unos usos repetitivos que se conocen como tradicionales. Un uso cultural que resulta necesario mantener y transmitir en el tiempo (del latín tradere, que da traditio, entregar o transmitir algo, considerado valioso, de valor, de una generación a la otra), para constituir una tradición. La tradición busca reproducir la estructura social y las prácticas culturales de un grupo. En lo que se conoce como identidad cultural, la tradición funciona como una hábil estrategia para sobrevivir e intentar perpetuarse, transmitiendo valores para preservar al grupo de los impactos que producen los cambios externos, asegurando a los miembros del grupo una cierta cohesión o unidad interna, mientras lo diferencia, a la vez, de grupos distintos, practicantes de otros usos. Si no se entregan esos valores como debe ser entre los miembros del grupo, se incurre en una traición (término derivado del mismo verbo latino tradere, que se especializó en una acepción diferente para designar la entrega de esa cosa valiosa, pero a alguien distinto al grupo, es decir, al enemigo u otro).

El comportamiento alimentario opera dentro de ese contexto como uno de los principales componentes sociales de la estrategia relacionada con la identidad cultural. El acto alimentario es un hecho cultural y social en el que operan estructuras de poder, jerarquías y sistemas de subordinación, cuyos cambios ocurren en el largo plazo. La tradición alimentaria no impide el cambio en el comportamiento alimentario, sino que lo hace más lento, tan lento que parece imperceptible. Lo que Fernand Braudel (1958) llamó “la longue durée”, un nivel histórico que asegura una cierta estabilidad en el largo plazo. 
En el acto alimentario se consumen, a la vez, alimentos y símbolos. Símbolos que son, en realidad, metáforas de esos alimentos que alimentan el cuerpo y el espíritu, y los insertan en una cosmología o concepción del mundo. Es de elevado interés para la sobrevivencia del grupo preservar esa concepción del mundo, y transmitirla. Una representación del mundo que se entrega como legado a los descendientes. Se trata de un conjunto de normas de comportamiento social que sirven de base y asidero para perseverar en la vida, mientras se intenta comprender el sentido individual de la existencia. Símbolos necesarios para que el individuo se inscriba como un ser social en el seno de una cultura determinada, donde se come, en grupo, para compartir, relacionarse, festejar, conmemorar, seducir, aparentar, negociar, tramar, impresionar, es decir, para comportarse como un ser social y actuar de una manera diferente a la de aquel animal que come en solitario para solo nutrirse.

Haré brevemente dos reflexiones que considero de importancia, antes de entrar en el tema de los regímenes alimentarios amazónicos.

La primera reflexión es que el consumo simultáneo de alimentos y símbolos está íntimamente relacionado con el ser humano, y se funde en lo que se ha llamado una dieta. Pero no en la dieta de los dietistas, o propia de los usos de la dietética, que recomienda cantidades y calidades de alimentos de acuerdo con categorías específicas de consumidores. No es a esa dieta a la que me refiero. Es a la dieta tal como la veían los antiguos filósofos griegos. La palabra dieta deriva de la voz griega díaita, que significa estilo, modo o género de vida. Para los griegos, díaita se refería a una serie de alimentos y de ejercicios gimnásticos que permitirían al individuo alcanzar un equilibrio armónico entre el cuerpo, la mente y el espíritu, tratando de mantener la mayor parte de la vida un peso similar, sin casi oscilaciones. En ese concepto se inscribe el pensamiento de Hipócrates, considerado el padre de la medicina, y también el padre de la dietética. Hipócrates prescribía hace unos 2500 años que "tu alimento sea tu mejor medicina, y que tu mejor medicina sea tu alimento”. Varios siglos más tarde, el poeta latino Juvenal acuñó su célebre máxima "mens sana in corpore sano” (mente sana en cuerpo sano). Los antiguos sabios griegos y romanos consideraban que la dieta es uno de los fundamentos para lograr el equilibrio necesario para la vida. La salud es la expresión del mantenimiento del equilibrio interno. La enfermedad era, para Hipócrates, el resultado de un desequilibrio corporal que se expresa a través de lo observado en cuatro humores: sangre, flema, bilis negra y bilis amarilla. La salud o el equilibrio perdido en esos humores podía reestablecerse al ingerir alimentos que fuesen de naturaleza contraria a la enfermedad. Por ejemplo, para personas con temperamento frío, como los ancianos, los melancólicos y los flemáticos, se recomendaba el consumo de alimentos calientes y secos, como la carne y el vino. Para lograr eso había que clasificar a los alimentos de acuerdo con su naturaleza, y a las personas de acuerdo con su temperamento. Esas categorías se aplicaron en varios sistemas del conocimiento a lo largo de la evolución de la humanidad. Puede aplicarse, por ejemplo, a la medicina tradicional china, cuyos pilares son, desde hace más de 3000 años, la dietética, la acupuntura y los masajes terapéuticos o tuinao. La dieta, en esa concepción, se emplea como un medio preventivo y curativo para reestablecer el equilibrio entre el yin y el yang, valiéndose, además, de la meditación y del ejercicio físico. Entre los indígenas, en particular entre los chamanes o curanderos, se usa el término de dieta para designar a la preparación que se da a una persona antes de que tome ayahuasca, con el fin de predisponerlo a la obtención de un equilibrio corporal integral distinta a la dieta alimentaria amazónica. En los orígenes de la dieta mediterránea y de la dieta de las comunidades nativas amazónicas, estuvo presente, también, el tema del equilibrio y el papel que juegan los alimentos para reestablecerlo y combatir la enfermedad. 
La segunda reflexión es que todo eso que llamamos alimento, una sustancia que sirve para alimentar, tiene una triple dimensión, que nutre, cura y significa. Es decir, esa sustancia es, a la vez, alimento, medicamento y símbolo. El término alimento procede del verbo latino alere, que significa alimentar, criar, nutrir, hacer crecer (de donde procede también alumnus, alumno, es decir, alimentado). Cuando me inicié en el estudio del tema de la socioantropología de la alimentación, rehuía las lecturas relacionadas con las plantas y los animales medicinales, es decir, la etnobotánica y la etnozoología. Lo mismo me sucedía con las pequeñas historias simbólicas que se ocultaban tras los alimentos, porque los símbolos juegan a ocultarse, hasta el punto de desvanecerse. Por ejemplo, como mencioné, el término alimento tienen la misma raíz lingüística que la voz alumno y alto. Ahora, muchos años más tarde, reconozco mi ceguera intelectual para comprender la esencia de las cosas que ingerimos. Que la alimentación es un hecho social total, presente desde el momento mismo de nuestro nacimiento, y aun antes; hasta nuestra muerte, y aun después. Que la alimentación es nuestro acto más íntimo, más que el acto sexual. Ambos nos construyen, pero la alimentación construye nuestro cuerpo y anima nuestro espíritu como si fueran ladrillos que dos albañiles juguetones, y sabios en teoría combinatoria, que se llaman ADN de la biología y ADN de la cultura, van colocando uno tras otro, e interrelacionándolos al mismo tiempo, para armar ese maravilloso y complejo rompecabezas que es la vida, que nos asegura la singularidad de una vida individual única e irrepetible.

\section{Objetivos y metodología para alcanzarlos}

En este artículo pretendo indagar sobre dos temas vinculados estrechamente. El primero es sobre los regímenes alimentarios amazónicos. Me pregunto básicamente cómo los miembros de las comunidades nativas amazónicas, y en especial los grupos indígenas que tienen un bajo grado de asimilación a las culturas urbanas y un escaso o incipiente nivel de contacto con el mercado capitalista, satisfacen sus necesidades alimentarias. Es decir, en qué consisten sus regímenes alimentarios. El otro tema es si, cuando los indígenas interactúan con la naturaleza para obtener sus alimentos (caza, pesca, chacra, recolección, etc.), aplicando sus métodos tradicionales de producción, consumo y distribución, en el marco de una especial cosmovisión, causan impactos ambientales que reducen la biodiversidad de su entorno.

Este estudio es, básicamente, el resultado de dos esfuerzos: uno lo constituye una ambiciosa investigación sobre la Amazonía peruana, que me llevó dos años de intenso trabajo en la recopilación de información en bibliotecas especializadas localizadas en Lima, y en particular en Iquitos. Esa experiencia me permitió desarrollar dos publicaciones, una en el año 2016, y otra, aún en proceso de edición. Con respecto a la ciudad de Iquitos, debo mencionar que funcionan dos grandes bibliotecas, ricas en materiales relacionados con diversos aspectos de la Amazonía: la del Instituto de Investigación de la Amazonía Peruana (IAAP) y la del Centro de Estudios Amazónicos (CETA). Precisamente, esta investigación consiste en una amplia revisión bibliohemerográfica, de índole descriptivo y cualitativo. Pero además, la investigación documental fue contrastada con los hechos observados de manera directa durante la estadía de un semestre que tuve en Iquitos. Desde esa ciudad, como centro de operaciones, pude visitar a varias comunidades nativas de la región Loreto, la entidad política administrativa de mayor extensión de la Amazonía peruana. Para la elaboración de un diccionario alimentario sobre la cuenca amazónica, ahora en proceso, hice otras visitas a las regiones amazónicas de Colombia, Ecuador 
y Venezuela. Complementé información, para este artículo, mediante entrevistas a nativos indígenas y a no nativos, entre ellos, a algunos funcionarios gubernamentales en la región amazónica.

\section{Resultados}

La dieta amazónica es una dieta tan singular como lo es la dieta mediterránea o la intervención dejian (cuerpomente), basada en la medicina tradicional china, que se nutrió, a su vez, de la filosofía budista zen y, en sus orígenes, del budismo de la India.

Desde el inicio hay que distinguir entre regímenes alimentarios amazónicos selváticos (que pueden ser llamados también rurales, aunque de manera impropia) y regímenes alimentarios urbanos. Los regímenes alimentarios urbanos no resultan, para mí, tan interesantes como los selváticos. Son, en realidad, regímenes resultantes del intercambio cultural, de la fusión, del mestizaje o de la transculturización. Este artículo trata sobre los regímenes alimentarios selváticos, más puros, propios de las comunidades nativas indígenas que habitan en las distintas regiones de la vasta cuenca amazónica.

Cada etnia indígena amazónica -hay más de 200 en la Amazonía - tiene su manera propia de alimentarse. No obstante, buscando puntos en común, se puede construir, con ciertas limitaciones, un modelo general de comportamiento alimentario simplificado.

Hacerlo en el caso de la actividad culinaria resulta una tarea relativamente sencilla. Una cocina es la transformación de un conjunto de ingredientes (vegetales, animales y minerales) en unas preparaciones alimenticias que se comen o se beben. Para realizar esa transformación química y mecánica, se emplea un saber culinario (compuesto por un agente culinario y un saber específico o receta), se utilizan métodos y técnicas (de preparación previa, conservación, condimentación, cocción, servicio y presentación) y se emplean utensilios y artefactos culinarios para facilitar esa transformación. Es decir, debemos estudiar, en una primera instancia, ingredientes, comidas y bebidas, técnicas de conservación y de cocción, y utensilios.

Al estudiar la flora y la fauna amazónicas, en general, observo que se repiten casi los mismos ingredientes en toda la cuenca amazónica. La diferencia está en la manera de designarlos, es decir, en los distintos nombres comunes utilizados. La salvedad radica en los casos regionales de endemismo. Los procesos de preparación del pescado de agua dulce (descamado y eviscerado) y de la carne de los animales de monte (a los que se despiezan y retiran las partes consideradas culturalmente incomibles, como el hígado) son similares en las distintas regiones amazónicas, al igual que las técnicas de conservación de los alimentos (básicamente el seco salado o charqueado y el ahumado). No hay cortes especiales de los alimentos. No existen prácticamente fondos de cocina. No se usan grasas para freír ni se recurre a frituras. Los principios de condimentación son casi iguales en toda la cuenca. Los métodos de cocción empleados son básicamente los mismos: el hervido y el asado. Las salsas se parecen: intervienen casi siempre el ají picante y el jugo amargo cocido de la yuca. Las bebidas alcohólicas y no alcohólicas se repiten en todas partes, aunque portan nombres distintos. El masato hecho de yuca dulce es la bebida privilegiada. En todas partes se consumen insectos, en particular larvas de coleópteros y hormigas. 
Para comprobar lo que acabo de afirmar, elaboré, para otra investigación, muchos cuadros de grupos de especies de flora (básicamente palmas, frutas, condimentos, raíces y tubérculos) y de grupos de especies de fauna (mamíferos, aves, reptiles, anfibios, peces e insectos). Cada cuadro comenzaba con el nombre científico de cada especie mencionada y después anotaba, a continuación, sus nombres comunes usuales en seis países de la cuenca amazónica (Bolivia, Brasil, Colombia, Ecuador, Perú y Venezuela). De ellos, solo tres (Brasil, Perú y Bolivia) son responsables del 92\% de la superficie total de la cuenca. Después seleccionaba las especies más importantes en cada grupo y género de la flora y la fauna. Cotejaba los cuadros para las distintas regiones amazónicas, y concluía que siempre coincidían al excluir las especies endémicas de cada grupo. En resumen, los ingredientes utilizados en la cocina, los ingredientes culinarios y las técnicas empleadas para la conservación y la cocción de los alimentos son, básicamente, similares entre los diferentes grupos étnicos de las distintas regiones de los países de la cuenca amazónica.

Las diferencias existentes entre los distintos regímenes alimentarios indígenas amazónicos no se encuentran en la esfera de los ingredientes, técnicas y utensilios empleados en la cocina, sino, probablemente, en el ámbito de la gastronomía. Esa suerte de envoltura de índole social que contiene a la cocina, incluyendo también las formas de producir, conservar, distribuir, preparar y consumir los alimentos. Todo eso que rodea a la cocina y sus usos, inscribiéndola dentro de una cultura determinada, tales como las maneras en la mesa y sus códigos, la gramática u orden en el consumo de los alimentos en cada comida, las prohibiciones de consumo o tabúes alimentarios, las preferencias, el folclore alimentario asociado (es decir: dichos, refranes, coplas, danzas), los rituales, los momentos cotidianos y especiales de consumo, los horarios de comida, los elementos propios de la cosmogonía, etc. Todo eso que conforma a la gastronomía, y que resulta, a la postre, como dijo Revel (1980), una metáfora de la cocina, tal como la cocina se expresa en una metáfora de la alimentación. Eso que corresponde a las prácticas y costumbres alimentarias que componen la superestructura de la alimentación o, usando otras palabras, a la ideología del acto alimentario, expresado en símbolos.

Al comparar las gastronomías de los distintos grupos étnicos amazónicos, me asombré de algunas semejanzas. Los principales tabúes alimentarios, por ejemplo, se parecían: en casi todos los grupos estaban presentes casi las mismas prohibiciones de consumo para las niñas que llegaban a la pubertad; el mismo rechazo a la sangre de la menstruación; los mismos tabúes alimentarios para las mujeres embarazadas. Parecidos tabúes relacionados con la caza o la pesca, que prohíben, por ejemplo, las relaciones sexuales y ver o tocar sangre menstrual antes de ir a cazar o a pescar, o que prohíben barrer la vivienda antes de salir a cazar. Parecidas creencias para realizar las actividades de caza, pesca o siembra. Similares rituales de paso o de transición de una etapa a otra de la vida. Casi las mismas estructuras de parentesco o de reglas para escoger pareja, y casi las mismas obligaciones existentes entre los distintos miembros de la familia. Igual división social del trabajo basada en el sexo, donde la mujer es la base de la familia y de la organización comunitaria, considerada el componente más bajo dentro de la escala social, pero la que ejecuta las labores más fatigantes, rutinarias e importantes para la vida de la comunidad indígena.

Las diferencias entre los grupos étnicos pueden estar, entonces, en sus cosmovisiones particulares.

Una cosmovisión es, según la antropología cultural, una visión estructurada y compartida por los miembros de un grupo social. En esa visión compartida se combinan de una manera coherente sus conocimientos sobre la 
vida y la muerte, el entorno, su inserción en el mundo y sus concepciones sobre el universo. Esa visión, de una enorme complejidad, se manifiesta en pautas de conductas sociales, convertidas en símbolos, que rigen la vida cotidiana de los miembros del grupo. Esas pautas son transmitidas de generación en generación dentro del grupo, como un aprendizaje cultural que depende de la capacidad que se tenga de usar símbolos (Geertz, 1991, p. 118). Como dice Gómez (2003, pp. 255-256): "La identidad étnica se expresa en diversas recreaciones del mundo y ethos comunitario a través de símbolos y rituales reconocidos en sistemas referenciales de la memoria oral”. La antropóloga Luisa Elvira Belaunde (2008, pp. 21-23), que comparó un amplio espectro de cosmovisiones amazónicas, concluyó que los distintos pueblos amazónicos están uniformizados en torno al culto de Luna, un mito basado sobre el origen de la sangre, la muerte y la reproducción. En una detallada revisión de las prácticas culturales alimentarias de las comunidades nativas de la Amazonía peruana, comprobé tales semejanzas (Cartay, 2016), que tienden a generalizarse a lo largo de toda la cuenca amazónica (Cartay, 2018). La escritora chilena Ana Pizarro (2012) estudió la manera cómo se construyeron los distintos imaginarios de la Amazonía en los discursos escritos y orales para concluir que la Amazonía es, en cierta manera, una unidad discursiva.

Si la cosmovisión es una estrategia cultural que utiliza un grupo social o comunidad para insertarse en el mundo y trascender, podemos preguntarnos, entonces, ¿qué relaciones existen entre la cosmovisión y la gastronomía de ese grupo?

La elección de los alimentos, la manera de alimentarse, de cocinar, de consumir y de «pensar» los alimentos (es decir, de otorgarles algún significado relevante), constituye, para mí, la gastronomía de un grupo o comunidad humana. La gastronomía, que es una expresión metafórica, opera como una actividad compleja que refleja de manera notable la cosmovisión del grupo que la aplica. Se manifiesta por la vía de las normas comunitarias de comportamiento frente a la sustancia, comida o bebida, que nutre al cuerpo y al espíritu, y da sentido al acto alimentario como un hecho social total dentro de una cultura determinada.

En las comunidades indígenas de la Amazonía, aisladas de manera voluntaria o forzosa, que tienen poco contacto con otras culturas o que presentan un escaso nivel de aculturación, cada planta, con cada parte utilizable (fruto, hoja, corteza, raíz, flor, etc.), y cada animal, porta un carácter distintivo que le otorga una triple dimensión (alimento-medicamento-símbolo). Esa triple dimensión compartida se ordena en un sistema clasificatorio donde los alimentos son considerados fríos o calientes, y tienen una clara pertenencia al entorno. Ese conocimiento se fue construyendo en estrecha relación con la naturaleza, en medio de enormes dificultades, durante siglos. Hasta lograr una cierta estabilidad en la cual se desarrollaba una estrategia de sobrevivencia del grupo. Ese estatus se fijó y transmitió entre generaciones como un valor cultural con la etiqueta de un saber ancestral.

Cada especie de la flora y de la fauna relevante para la vida de un grupo étnico tiene, en ese ámbito, una representación. Es decir, un alma y un dueño, al cual uno debe solicitarle permiso antes de poseerla. Las actividades de subsistencia (caza, pesca, chacra y recolección) solo son óptimas cuando se establece una relación con el jefe del ámbito o con los dueños, basada en un compromiso de reciprocidad. Esa posesión no puede ser abusiva, contraria a su propia sobrevivencia como especie. Es el 'otro' el que extingue o pone en peligro la existencia de una especie, no el grupo comunitario que la usa, la preserva y la reproduce (domesticando plantas, por ejemplo), respetándola por ser el soporte de su vida. El indígena amazónico vive no solo en relación con la 
naturaleza, sino con la naturaleza y dentro de esta, entretejiéndose entre los seres humanos y los seres 'naturales' una relación estrecha y compleja que se manifiesta a través de los relatos cosmogónicos. A esa relación armoniosa con el cosmos, el indígena amazónico llega estableciendo una pauta de entendimiento con el entorno, mediada por el antropomorfismo. Entonces, cada planta, animal o elemento de la naturaleza, el sol, la luna, el río, el bosque, adquiere vida, un ánima. Un cazador, al identificarse empáticamente con el animal que intenta cazar, tiene el 'poder' de predecir los movimientos de su presa. Algunas personas, muy sensibles y entrenadas rigurosamente para tal fin, como sucede con los chamanes, pueden relacionarse con los elementos de la naturaleza, descubriendo seres de poder que protegen las especies con inteligencia y voluntad propia (Costa, 2013, p. 33). El chamán, utilizando algunas sustancias alucinógenas, como la ayahuasca y la chacruna entre otras, puede acceder a esa visión multidimensional, metafórica, con una fuerte carga simbólica. Las formas de alimentación se inscriben en el doble capital, como lo llamó Morin (2003, p. 184), integrado por el capital cognitivo y técnico (prácticas, saberes, reglas, saber-hacer) y el capital mitológico y ritual (creencias, normas, valores, prohibiciones). La alimentación y la gastronomía se mueven dentro de esas dos modalidades de capital. Ese capital de memoria y de organización es transmitido dentro del grupo indígena como reflejo de su ethos, término empleado a la manera de Bordieu (1993, p. 85), es decir, como reglas, estrategias o constructos ideológicos, disposiciones inconscientes, predisposiciones y prácticas habituales que dan forma a la ideología, convirtiéndola en el producto histórico de un conjunto de condiciones subjetivas de existencia. La persona interioriza el paisaje y lo convierte en un elemento que desempeña un papel protagónico en su vida diaria. De esa manera, el ethos se convierte en una cosmovisión compartida y difundida a otras comunidades, aún lejanas, a través del funcionamiento de redes de intercambio, basadas la mayoría de las veces en relaciones igualitarias y no en relaciones de explotación o de coerción de élites indígenas (Colson, 1985; Meggers, 2003, pp. 24-25).

Para un indígena amazónico, y seguramente también para comunidades indígenas de otras partes, no existe una separación estricta entre individuo y sociedad, entre orden material y orden social, entre cultura y naturaleza. Actúa, dentro de ese ámbito, "como alguien que está junto a las cosas, como miembro de una comunidad mayor, planetaria y cósmica” (Boff, 2011, pp. 14-15). Ese proceder o manera de comportamiento en el seno de una cultura diferencia a un indígena de la selva amazónica de un ciudadano perteneciente a un entorno capitalista occidental, en el que el individualismo y los modelos de consumo corresponden a valores compartidos en esa esfera. En este caso, el individuo se comporta "como un ser sobre las cosas, disponiendo de ellas a placer" (Boff, 2011, p. 14). Se trata de dos modelos contrapuestos de comportamiento en relación con la naturaleza, que Varese (2011, p. 36) llama “modelo cosmocéntrico”, el amazónico, y “modelo antropoeconocéntrico”, al que responde la economía de mercado capitalista.

En el seno de una comunidad indígena amazónica se actúa dentro del marco de unos valores compartidos dentro del grupo, más que con el grado aparente de libertad en la elección que un individuo ejerce en una sociedad occidental capitalista. En ambas, la personalidad, individual y social, es la resultante de factores biológicos, vinculados con la genética, y de factores ambientales, vinculados con la cultura. Las dos se diferencian, sin embargo, en la manera cómo la naturaleza se 'mete' en la cultura. En el capitalismo tiende a subordinarse a la naturaleza en relación con la cultura, justificando esa conducta con la noción de progreso. En las comunidades amazónicas la naturaleza es incorporada en un plano de igualdad con la sociedad. Para la Comisión Amazónica 
de Desarrollo y Medio Ambiente (1994, p. 97), “la lección más importante de los pueblos indígenas es, sin lugar a dudas, su inserción en los ecosistemas y su estrecha interrelación con ellos, buscando su calidad de vida con gran respeto por el entorno”. El concepto de ‘dueño’ que mencioné antes, y que desempeña un papel ambivalente de amenaza-protección, actúa como un intermediario o mediador entre los hombres y la naturaleza, transmitiendo las reglas de uso sin las cuales el orden general de las relaciones hombre-naturaleza quedaría perturbado (Chaumeil, 1994, p. 230; Macera \& Casanto, 2011, p. 77; Seitz, 2007, p. 127).

La sociedad indígena amazónica selvática, con escaso contacto cultural con sociedades urbanas y el mercado, funciona sometida a equilibrios hidrostáticos, una condición clave para lograr la estabilidad de un sistema, en el que la compresión a que se somete un recurso, se equilibra con la presión que genera una fuerza en dirección contraria. Son sociedades de respeto a la naturaleza, donde no hay prácticamente excedente económico ni casi técnicas o sistemas de conservación de los alimentos, sin que exista una fuerte preocupación o ansiedad para acumular riquezas materiales. Son sociedades que confieren atributos sociales a las plantas y a los animales, a los que considera como sujetos más que objetos, que no son expulsados a esferas distintas de la vida regidas por la ley del mercado y del capital, y que no están sometidos a la subordinación progresiva por la ciencia, la tecnología y el gran capital, tal como sucede en las sociedades capitalistas occidentales (Descola, 2005, p. 391). La sociedad indígena es una sociedad que resulta movida por reglas y mecanismos distintos a los que operan incluso en los de regímenes socialistas, insertos en marcos regidos por sistema de planificación central, que subordinan la mayoría del colectivo a una estructura de decisión, poder, jerarquías y privilegios establecidos por una nomenclatura de élite o que están regidos por los intereses del comité central del partido comunista en el poder.

Las consideraciones anteriores que he realizado, no son, sin embargo, compartidas por todos los investigadores del tema. Para no dar la impresión de que hablamos sin oír al otro, intentaré resumir los argumentos expresados por la otra parte, que considera que esa relación de armonía de las comunidades nativas indígenas amazónicas con la naturaleza es una posición subjetiva, que se ha mitificado y que no existe en la realidad un relacionamiento armónico tal como lo hemos expuesto. Se trata del dilema del salvaje ecológicamente responsable (Ecologically Noble Savage), que cuenta con el respaldo de prestigiosos investigadores y de una abundante y seria bibliografía que debe ser tenida en cuenta.

Según Hames (2007), uno de los expositores más conocidos, este debate tiene dos maneras distintas de enfocarlo. Una hace referencia a la cuestión de la conservación de la naturaleza entre los pueblos nativos indígenas, apoyándose en los estudios sobre el uso de los recursos que han realizado etnógrafos, arqueólogos e historiadores. La otra es más amplia en su planteamiento, la cual, aborda la cuestión con una mayor orientación humanística y política, viéndola en términos de identidad cultural, conocimientos ecológicos e ideológicos, usando el elemento de nobleza ecológica como un instrumento político planteado por los pueblos nativos organizados y por los grupos conservacionistas.

De acuerdo con Ellingson (2001) el término de noble savage fue usado en inglés por primera vez por Dryde, en 1672, que lo tomó del explorador francés Lescarbot, y luego erróneamente atribuido a J. J. Rousseau, quien lo popularizó como el mito del buen salvaje. Tomado luego por los conservacionistas en el siglo XIX, promovió 
la idea de que los indígenas vivían en armonía con la naturaleza. Esa idea fue reforzada después por la ecología cultural, cuando Odum (1972) planteó la teoría del flujo de energía (los ecosistemas se organizan en sistemas que tienden al equilibrio, a la estabilidad). Wynne-Edwards (1962) había argumentado antes que las especies estaban envueltas en una serie de adaptaciones que las previene de la degradación de sus hábitats. Estas condiciones (estabilidad y vida armónica) fueron el soporte teórico de la ecología cultural. Algunos investigadores se opusieron, porque les parecía superficial la idea de la vida armónica indígena. Argumentaron, basándose en los continuos enfrentamientos bélicos entre los grupos indígenas, y en que algunas degradaciones del ambiente fueron cometidas por las sociedades indígenas de los trópicos húmedos, pero tuvieron bajo impacto porque, dicen, existía una baja densidad poblacional en vastos espacios. Entonces, una alta biodiversidad se asociaba con la presencia de los pueblos indígenas nativos, y una baja biodiversidad con la existencia de pueblos de colonizadores urbanos. En la década de 1980 aparecieron dos importantes trabajos que presentaron serias evidencias de la destrucción ambiental por parte de algunos grupos indígenas. Se trató de las obras de dos investigadores, el etnógrafo Rambo (1985) y el geógrafo cultural Diamond (1986). Después apareció el libro clásico de los que se oponen a la tesis del buen salvaje: el libro de Redford, The Ecologically Noble Savage, publicado en 1991, en el que se exponía la idea de que la conservación intencional de la naturaleza por parte de los indígenas era un mito. Redford (1999) volvió luego al tema. Señalando que las comunidades indígenas otorgan por interés económico derechos para explotar sus reservas (madera y minas), explotan comercialmente la flora y la fauna y reciben a los turistas para mostrarles sus ‘tradicionales estilos de vida’. Según Redford, no vacilaron en adoptar las armas de fuego para la caza. Otros (Alvard, 1998; Hunn, 1982; Rambo, 1985; Redford \& Robinson, 1987) ya habían presentado algunas evidencias sobre los daños ambientales. Después vinieron otros (Elligson, 2001; Hames, 2007; Nadasdy, 2005; Redman, 1999; Rudel, Bates, \& Marchingulashi, 2002; Zapata, 2001; Zapata, Urgilés, \& Suárez, 2009). Otros (Conklin, 1997; Krech, 1999) que señalaron que el ambiente de la discusión sobre el debate se había escapado un poco de la academia, y se había ‘contaminado' con la intervención de algunas organizaciones de ambientalistas y conservacionistas que 'usan', dicen, a los indígenas para desarrollar sus propias agendas de trabajo. Presentan a los indígenas como guardianes del bosque, conservacionistas naturales durante siglos, dueños de saberes ancestrales y de valores espirituales que los predisponen a vivir en armonía con la naturaleza, como si las sociedades indígenas fueran entidades homogéneas fijadas en el tiempo (Conklin, 1997, p. 713).

\section{Discusión}

De entrada admito que este artículo tiene varias limitaciones. La primera, y más importante, es que la falta de espacio de un artículo impide que nos refiramos en extenso a las distintas actividades productivas de las comunidades, sus saberes ancestrales y sus prácticas culturales más usuales, fundadas en su cosmovisión para argumentar en pro de nuestro punto de vista de la relación equilibrada entre indígena selvático y naturaleza, con un mínimo de daño medioambiental. La segunda es que, también por razones de espacio, opté por examinar con preferencia a los regímenes alimentarios de los grupos que han tenido contactos moderados con las sociedades urbanas. Sus comportamientos, como es obvio, no reflejan en toda su magnitud la influencia de las nuevas tecnologías introducidas por los colonos en la zona (como armas de fuego, deforestación masiva, extracción ilegal de madera, plantaciones de coca y penetración creciente del narcotráfico, pesca de arrastre, caza furtiva con fines comerciales, etc.) y sus prácticas invasivas que han causado, junto con la apertura de las carreteras y 
las explotaciones de minería y de petróleo, irreparables daños ambientales en una extensa parte de algunos de los países de la cuenca amazónica. De acuerdo con esa doble perspectiva, donde encontramos a comunidades indígenas nativas de escasa asimilación de otras culturas versus comunidades indígenas con un mayor y frecuente grado de contacto con culturas urbanas y con el mercado, se derivan dos comportamientos distintos en cuanto a regímenes alimentarios se refiere. Esos dos regímenes se manifiestan, en la práctica, produciendo distintos niveles de impacto, de menor a mayor impacto, sobre la conservación de la biodiversidad amazónica. En este trabajo, yo he optado claramente por la primera de las posibilidades: la perspectiva de que la constitución y el mantenimiento de los regímenes alimentarios de sociedades indígenas de escaso contacto cultural con la sociedad urbana, presenta moderados impactos sobre el ambiente para satisfacer sus necesidades, mientras realiza aportes para aumentar la biodiversidad. Es innegable que los grupos amazónicos practican una agricultura migratoria de subsistencia que tala parcialmente una parcela de bosque, que va desde $405 \mathrm{~m}^{2}$ a $2632 \mathrm{~m}^{2}$ por consumidor (Descola, 2005, p. 235), que luego rozan y queman, para establecer chacras de policultivo que se cultivan durante un tiempo que va de seis a diez años, que luego abandonan para convertirse en purma. Pero tras 15 a 20 años de descanso, es cubierta nuevamente por bosque secundario. Cuando ese sistema es aplicado de manera intensiva se puede producir una gran deforestación, que Kauffman et al. (2013, pp. 48-49) llama “andinización de la selva”, tal como hicieron los indígenas Chachapoyas en la selva alta. En efecto, ese daño puede ocurrir en una pequeñísima escala, muy diferente a los grandes procesos de deforestación estimulados por la agricultura comercial. No obstante, también se disponen de numerosas evidencias antropológicas que revelan que numerosas comunidades han desarrollado muchas variedades de sus productos básicos, adaptándolas a sus necesidades. Las mujeres awayún cultivan en sus chacras de 20 a 30 variedades de yuca, de 200 que reconocen (Seitz, 2007, pp. 128-132). Los shipibo-conibo siembran 11 variedades de yuca (Morin, 1998). Los maihuna siembran 15 variedades de yuca y 16 de plátanos (Bellier, 1994). Los yagua cultivan 6 variedades de yuca (Chaumeil, 1994). Los ticuna cultivan 16 variedades de plátano (Goulard, 1994). Los mayoruna siembran 5 variedades de yuca, 9 de plátano y 3 de maíz (Erikson, 1994). Los uni cultivan 15 variedades de plátano (Frank, 1994). Los matsigenka cultivan 30 variedades de plátano y 30 de yuca (Resengren, 2004). Los bora siembran 32 variedades de yuca y 14 de maní (Flores, 2000, p. 370-375). Muchos grupos establecen la chacra y un huerto familiar donde realizan tareas de conservación de la agrobiodiversidad, donde introdujeron especies silvestres y las domesticaron, difundiendo su utilidad (Flores, 2000, p. 375).

Un poblador amazónico, poco afectado por los procesos de cambio sociocultural, consigue, de ordinario, su alimentación cada día y en la cantidad de calorías que requiere a partir de cuatro fuentes: pesca, caza, chacra y recolección. Recurrir al mercado es una posibilidad, pero no usual. Los carbohidratos necesarios los obtiene básicamente de la chacra, la proteína y las grasas de la caza, la pesca y la recolección (en especial de drupas de palmas, de insectos comestibles y de huevos de tortugas). El bosque, y en especial el río, constituyen la despensa, una despensa donde se obtienen los nutrientes sin costo monetario, sino con un costo en energía y tiempo. El agua es como un supremo sacerdote que impone su ley en la Amazonía profunda. El agua es la fuente de la vida y los ríos son sagrados. Recordemos que numerosos pueblos amazónicos comparten el mito originario del gran diluvio. La Amazonía fue originalmente el lugar donde ocurrió un verdadero diluvio, hace 60 millones de años, cuando surgió la cordillera andina y se creó un extenso lago de agua dulce que perduró hasta el Pleistoceno, cuando se vació para ser ocupado por la selva amazónica. El calendario y las actividades amazónicas se ordenan 
de acuerdo con las crecientes y vaciantes de sus ríos, valiéndose de una serie de indicadores que pertenecen al saber ancestral, que Levi-Strauss (1975, pp. 35-40) llamó “ciencia de lo concreto”, un conocimiento construido a través de una actividad mental que relaciona los fenómenos a partir de sus cualidades sensibles.

En la selva adentro, al lado de los numerosos ríos que crean un intrincado tejido de cuerpos de agua, algunos con abundancia de especies piscícolas, especialmente en los ríos de aguas blancas, que nacen en las cumbres andinas, persiste una gastronomía originaria, aún no intervenida por economías externas conectadas con el medio urbano. Se trata de una gastronomía que privilegia el alimento fresco, que excluye prácticamente el uso de productos procesados industrialmente, que se basa en sistemas de cocción del hervido o sancochado y el asado, que restringe el uso de preparaciones fritas (salvo cuando se utilizan insectos comestibles o drupas de palmeras, que se usa la propia grasa del alimento), que evita el uso excesivo de la sal (con el sistema pango), del azúcar y del condimento industrializado, que utiliza bebidas sustanciosas como el masato y desconoce las bebidas gaseosas. Ese régimen alimentario determinado por la biodiversidad del entorno, y alejado del mercado y de los modos de consumo alimentario urbanos, causa poco impacto sobre el medio ambiente.

En la medida que avanzan los procesos de transculturización y tocan las costumbres de las comunidades indígenas selváticas, cambia su estilo de vida, su díatia, y el mercado comienza a ejercer su influencia, una presión constante sobre la vida de la comunidad indígena, tanto sobre su fuerza de trabajo, convirtiéndola en mano de obra asalariada, como sobre las costumbres del grupo, entre ellas los usos alimentarios. Se producen, entonces, importantes cambios en la calidad de vida, y surgen desequilibrios persistentes en las relaciones del indígena con la naturaleza. Entre estos cambios está la degradación de su sistema alimentario, el debilitamiento de su seguridad alimentaria, la disminución de las disponibilidades de proteínas animales, el aumento de la cantidad de trabajo necesario para satisfacer las necesidades socialmente reconocidas, así como, la disminución del tiempo efectivamente dedicado al descanso, a la diversión, al ocio y a los encuentros sociales intergrupales, aparte de que la excesiva presión del mercado degrada el medio natural (Cartay, 2016, pp. 200-207) y convierte a muchos indígenas -debilitada su identidad y su orgullo étnico- en parias que sobreviven en las mayores ciudades amazónicas.

\section{Referencias}

Alvard, M. (1998). Evolutionary ecology and resource conservation. Evol. Athrop., 7, 62-74.

Belaunde, E. (2008). El recuerdo de Luna. Género, sangre y memoria entre los pueblos. Lima: CAAAP.

Bellier, I. (1994). Los maihuna. En F. Santos y F. Barclay (Eds.), Guía etnográfica de la alta Amazonía (Vol. 1, pp. 3-179). Quito: IFEA-FLACSO.

Boff, L. (2011). Ecología: grito de la Tierra y grito de los pobres. Madrid: Trotta.

Bourdieu, P. (1993). Outline of a Theory of Practice. Cambridge: Cambridge University Press.

Braudel, F. (1958). Histoire et Sciences Sociales: la longue durée. ANNALES, Economies, Sociétés, 13(4), 725-753.

Cartay, R. (2016). La mesa amazónica peruana. Ingredientes, corpus y símbolos. Lima: Universidad de San Martín de Porres.

Cartay, R. (2018). Diccionario enciclopédico de alimentación, cocina y gastronomía de la cuenca amazónica. Lima: Universidad de San Martín de Porres. 
Chaumeil, J. P. (1994). Los yagua. En F. Santos y F., Barclay (Eds.), Guía Etnográfica de la Alta Amazonía (Vol. 1, pp. 183-307). Quito: IFEA-FLACSO.

Colson, A. B. (1985). Routes of Knowledge: an aspect of regional integration in the circum Roraima area of the Guaiana Highlands. Antropologica, 63-64, 103-149.

Comisión Amazónica de Desarrollo y Medio Ambiente. (1994). Amazonía sin Mitos. Bogotá: La Oveja Negra.

Conklin, B. (1997). Body paints, feathers, and VCRs: A esthetics and authenticity in Amazonian activism. American Ethnology, 24, 711737.

Costa, A. E. (2013). Saberes ancestrales y epistemología amazónica en Las tres mitades de Ino Moxo de Cesar Calvo. En R. Virhuez (Comp.), Voces de la Selva. Ponencia del I Coloquio Internacional de Literaturas Amazónicas (pp. 28-37). Lima: Editorial Pasacalle.

Descola, P. (2005). Las lanzas del crepúsculo. Relatos jívaros de la Alta Amazonía. Buenos Aires: Fondo de Cultura Económica.

Diamond, J. (1986). The environmentalist myth. Nature, 24(324), 19-20.

Ellingson, T. (2001). Myth of the Noble Savage. Berkeley: University California Press.

Erikson, P. (1994). Los Mayoruna. En F. Santos y F. Barclay (Eds.), Guía Etnográfica de la Alta Amazonía (Vol. II, pp. 3-127). Quito: IFEA-FLACSO.

Flores, S. (2000). Agrodiversidad tradicional en el departamento de Loreto y su contribución a la seguridad alimentaria y al desarrollo sustentable amazónico. En F. Morales y C. Manrique (Eds.), Agrodiversidad en la región andina y amazónica. Lima: NGO-CGIAR.

Frank, E. H. (1994). Los uni. En F. Santos y F. Barclay (Eds.), Guía Etnográfica de la Alta Amazonía (Vol. II, pp. 133-209). Quito: IFEA-FLACSO.

Geertz, C. (1991). La interpretación de las culturas. México: Gedisa.

Gómez, M. (2003). Saber indígena y medio ambiente: experiencias en aprendizaje comunitario. En E. Leff (Coord.), La complejidad ambiental. México: Siglo XXI Editores UNAM-PNUMA.

Goulard, J. P. (1994). Los ticuna. En F. Santos y F. Barclay (Eds.), Guía etnográfica de la alta Amazonía (Vol. 1, pp. 309-443). Quito: IFEA-FLACSO.

Hames, R. (2007). The Ecologically Noble Savage Debate. Annual Review of Anthropology, 36, 177-190.

Hunn, E. (1982). Mobility as a factor limiting resource use in the Columbian Plateau of North America. En N. William y E. Hunn (Eds.), Resource Managers: North America and Australian Foragers (pp. 17-43). Denver, Co: Westview Press.

Kauffman, F. et al. (2013). Los chachapoyas. Lima: Banco de Crédito.

Krech, S. (1999). The Ecological Indian: Myth and History. New York: Norton.

Lévi-Strauss, C. (1975). El Pensamiento Salvaje. México: FCE.

Macera, P., \& Casanto, E. (2011). La cocina mágica Asháninka. Lima: Universidad de San Martin de Porres.

Meggers, B. J. (2003). Fuentes naturales versus fuentes antropogénicas de la biodiversidad amazónica: la continua búsqueda de El Dorado. Amazonía Peruana, XIV, 28-29, 7-10.

Morin, E. (2003). El Método. La humanidad de la humanidad. La identidad humana. Madrid: Ediciones Cátedra.

Morin, F. (1998). Los shipibo-conibo. En F. Santos Granero y F. Barclay (Eds.), Guía Etnográfica de la Alta Amazonía (Vol. III). Quito: IFEA-Smithsonian Tropical Research Institute.

Nadasdy, P. (2005). Trascending The Debate over the Ecologically Noble Indian: Indigenous Peoples and Environmentalism. Ethnohistory, 52(2), 291-331.

Odum, H. (1972). Environment, Power, and Society. New York: Wiley.

Pizarro, A. (2012). Amazonía: el río tiene voces. Santiago de Chile: Fondo de Cultura Económica Chile. 
Rambo, A. T. (1985). Primitive Polluters: Semang Impacts on the Malaysian Tropical Rain Forest Ecosystems. Anthropological Papers, 76, 76-79.

Revel, J. F. (1980). Un festín en palabras. Barcelona: Tusquets Editores.

Redford, K. H. (1999). The Ecologically Noble Savage. Cultural Survival Quarterly, 15(1).

Redford, K., \& Robinson, J. (1987). The game of choice: patterns of Indian and Colonist hunting in the Neotropics. American Anthropologist, 89, 50-66.

Redman, C. (1999). Human Impact on Ancient Environment. Tucson: University Arizona Press.

Resengren, D. (2004). Los matsiguenka. Santos Granero, F.; Barclay, F. (Eds.). Guía Etnográfica de la Alta Amazonía. Vol. IV, 5157. Quito: IFEA-Smithsonian Tropical Research Institute.

Rudel, J. K., Bates, D., \& Marchingulashi, R. (2002). Ecologically Noble Amerindians? Cattle Ranching and Cash Cropping among Shuar and Colonists in Ecuador. Latinamerican Research Review, 37(1), 144-159.

Seitz, G. M. (2007). Ruptura generacional en las comunidades nativa awayun shushug, nayampim y wawas durante las últimas décadas SEPIA. Género y gestión de recursos naturales, 125-150. Lima: SEPIA.

Varese, S. (2011). Conferencia inaugural Amazonía. En J. P. Chaumeil, O. Espinosa de Rivero y M. Cornejo (Eds.), Por donde hay soplo. Lima: IFEA/PUC Perú/ CAAAP/ Centre EREA du LESC.

Wynne-Edwards, V. (1962). Animal Dispersion in Relation to Social Behavior. Edinburgh: Boyd \& Oliver.

Zapata, G. (2001). Sustentabilidad de la cacería de subsistencia. El caso de cuatro comunidades quichuas de la Amazonía ecuatoriana. Mastozoología Neotropical, 8(1), 59-66.

Zapata, G., Urgilés, C., \& Suárez, E. (2009). Mammal hunting by the Shuar of the Ecuadorian Amazon: is it sustainable? Oryx, 43(3), 375-385.

Rafael Cartay

Profesor jubilado de la Universidad de los Andes (ULA), Mérida, Venezuela. Profesor investigador de la Universidad Técnica de Manabí (UTM), Portoviejo, Manabí, Ecuador. Ha sido investigador externo de la Universidad de San Martín de Porres, Lima, Perú.

rafaelcartay@gmail.com 